\title{
MRI Contribution in the Diagnosis of Non-Traumatic Medular Compressions at the Mali Hospital of about 179 Cases
}

\author{
Mody Abdoulaye Camara1*, Mamadou N'Diaye², Mamadou Bakary Coulibaly3, \\ Mohamed Maba Traore', Hawa Diarra', Boubacar Mama Toure'1, Abourahman Abdillahi Nour', \\ Salia Coulibaly4, Ilias Guindo4, Madani Ouologuem5 ${ }^{5}$, Sounkalo Traore6, Mahamane Mariko7, \\ Aphou Sallé Kone ${ }^{8}$, Moussa Konate ${ }^{9}$, Siaka Sidibe ${ }^{9}$
}

${ }^{1}$ Medical Imaging Department of Mali Hospital, Bamako, Mali

${ }^{2}$ Radiology Unit of the Bamako Infirmary Hospital, Bamako, Mali

${ }^{3}$ Gynecology Department of Mali Hospital, Bamako, Mali

${ }^{4}$ Medical Imaging Department at Kati University Hospital, Bamako, Mali

${ }^{5}$ Neurology Unit of the Bamako Infirmary Hospital, Bamako, Mali

${ }^{6}$ Radiology Unit of the Reference Health Center of the Commune V, Bamako, Mali

${ }^{7}$ Medical Imaging Department of CHME Luxembourg, Bamako, Mali

${ }^{8}$ Radiotherapy Department of Mali Hospital, Bamako, Mali

${ }^{9}$ Radiology Department of CHU POINT G, Bamako, Mali

Email: *drmacamara@yahoo.fr, ndiayemedecin@yahoo.fr, mbccolby1@yahoo.com, saliacoulib@gmail.com, uodba2@hotmail.com, hawadiarra10@yahoo.fr, mohamedmaba@yahoo.fr, boubacarbassan@gmail.com, ouolmad@yahoo.fr, aphousalle@yahoo.fr, ilias.guindo2000@gmail.com,sounkalo.t@yahoo.com,M1_@hotmail.com, sidibes@hotmail.com

How to cite this paper: Camara, M.A., N’Diaye, M., Coulibaly, M.B., Traore, M.M., Diarra, H., Toure, B.M., Nour, A.A., Coulibaly, S., Guindo, I., Ouologuem, M., Traore, S., Mariko, M., Kone, A.S., Konate, M. and Sidibe, S. (2020) MRI Contribution in the Diagnosis of Non-Traumatic Medular Compressions at the Mali Hospital of about 179 Cases. Open Journal of Medical Imaging, 10, 186-195.

https://doi.org/10.4236/ojmi.2020.104017

Received: May 26, 2020

Accepted: December 27, 2020

Published: December 30, 2020

\begin{abstract}
Slow spinal compressions are due to the development of an expansive process in the spinal canal. It is a very common pathology, the diagnosis of which is mainly clinical. However, magnetic resonance imaging occupies an essential place in the site diagnosis and etiological research in the management. Non-traumatic spinal cord compression is a diagnostic and therapeutic emergency, requiring early and appropriate management. MRI is the benchmark imaging examination for this pathology. No similar previous MRI study in Mali. We undertook this work with the aim to determine the place of MRI in the diagnosis of spinal cord compressions in Mali hospital. Method and Patients: This was a descriptive retrospective study, carried out at the hospital's medical imaging department from January 1, 2017 to December 31, 2018 (02 years). It involved all patients, regardless of sex and age, sent for an MRI examination of the spine, and in whom spinal cord compression was diagnosed. We used a $0.35 \mathrm{~T}$ low-field MRI machine with solid-state antennas. Results: We collected 179 cases of spinal cord compression MRI out of 585
\end{abstract}


Copyright $\odot 2020$ by author(s) and Scientific Research Publishing Inc. This work is licensed under the Creative Commons Attribution International License (CC BY 4.0). http://creativecommons.org/licenses/by/4.0/ spinal MRI performed, (frequency of 30.59\%). The average age was 53.5 years with a male predominance (sex ratio 3.7). Motor disorders were the most common reason for examination (41\%). We used the T1 T2 sagittal and T2 axial sequences. IV injection of gadolinium was performed in $48 \%$ of patients. The topographic lesions were: cervical (54.7\%), thoracic (31.3\%) and several segments (9.5\%). The lesions concerned the compartments: extradural (79.3\%), intradural $(4.5 \%)$, and intramedullary (16.2\%). The processes were degenerative (57.5\%). tumorous (29.6\%), infectious (12.3\%) and vascular $(0.6 \%)$. Conclusion: MRI is the benchmark imaging test for the management of non-traumatic spinal cord injury. Myelo-CT can be an alternative in the absence or in case of MRI contraindication.

\section{Keywords}

Spinal Cord Compression, Non Traumatic, MRI, Mali Hospital

\section{Introduction}

Slow spinal compressions are defined as non-traumatic pathological processes which, through mechanical and/or vascular phenomena, lead to a progressive loss of spinal functions, the outcome of which is a flaccid paraplegia or tetraplegia [1] [2]. It is a diagnostic and therapeutic emergency [1] [3]. The clinical picture must be quickly recognized and investigated because the therapeutic sanction, often surgical, must be carried out as quickly as possible. The main challenge in this context is often to make the diagnosis as early as possible in order to limit the functional consequences of compression [1]. Today, MRI remains the benchmark examination for the emergency management of spinal cord compression syndrome. This MRI must be performed in an immediate emergency, as soon as the diagnosis is suspected from the clinic [3]. Management is urgent to promote recovery or avoid worsening. Depending on the etiology of the compression, it is proposed: surgery, medical treatment of infectious causes, or chemotherapy/radiotherapy for the tumor process inaccessible to surgery [1] [3] [4]. MRI has indisputably simplified the diagnostic and therapeutic process. Examination is performed without or combined with the injection of gadolinium. In fact, in a single exploration, it provides most of the information provided in stages by traditional methods: reference spinal cord deformation with respect to compression, alterations of the parenchyma in the form of abnormal spinal signals, direct visibility of the causal lesion and structuressatellites (cysts), LCS blockage, morphological and static abnormalities of the spine. Most of the time is sufficient to establish the surgical indication, MRI has supplanted here the other methods which owe their survival only to accessibility or deferred to MRI imaging [4]. A good knowledge of the spinal anatomy and functional neurological often makes it possible to orient the explorations and the topographic diagnosis [1]. 
No previous study had dealt with MRI aspects in Mali. We undertook this work with the aim of determining the place of MRI in the diagnosis of non-traumatic spinal cord compressions in the medical imaging department of the Mali hospital.

\section{Patients and Methods}

This was a descriptive retrospective study, carried out at the hospital's medical imaging department from January 1, 2017 to December 31, 2018 (02 years). Were included in our series; any patient, regardless of sex and age, with non-traumatic spinal cord compression, confirmed by MRI at Mali hospital and during the study period.

The variables studied were: socio-demographic data (age and sex), Neurological disorders (pain, sensory or motor disorders, sphincter disorder, and spinal cord compression syndrome). Spinal region (cervical, thoracic and lumbar). MRI aspect: sequences T1, T2, morphology, signal, enhancement after injection of gadolinium and the site. The MRI diagnostic hypothesis focused on lesions: tumoral, infectious and degenerative of the spine. The data was collected from the MRI registry, the examination report (s) and digital images in the database. Data analysis was done with SPSS 22.0 software. Procedure for the MRI examination: All the patients had benefited beforehand from a psychological preparation which consisted of explaining the purpose, the procedure of the examination and the search for contraindications. Before entering the MRI room, patients were cleared of any ferromagnetic objects that contraindicated the examination or that could generate artifacts. After they were installed on the examination table (in supine position, the volume type antenna was placed around the region of interest. We used the sequences: T1, T2, T2 sagittal STIR, and T2 axial. The latter was supplemented or not by sagittal sequences and a $\mathrm{T} 1$ in the plans with an intravenous injection of the gadolinium salt at a dose of $0.1 \mathrm{ml} / \mathrm{kg}$. The thickness of the cuts was $05 \mathrm{~mm}$ every $05 \mathrm{~mm}$ [5].

\section{Results}

\subsection{Socio-Demographically}

In two years, we had collected 179 patients with slow non-traumatic spinal cord compression out of 585 patients who underwent MRI of the spine, a frequency of $30.5 \%$. The average age of our patients was 53.5 years with extremes ranging from 9 to 94 years. The male sex represented $78.8 \%$ of our patients (sex ratio of 3.7). The clinical information was: motor disorders (35.2\%), spinal pain (16.2\%), or sensory disorders (30.7\%) Table 1. The spinal stages explored: cervical (55.3\%) and thoracic (31.3\%) and lumbar (3.9\%) Table 2.

\subsection{On the MRI Plan}

All our patients benefiting from the sequences: sagittal (T1, T2) and axial T2 among them $48 \%$ received an intravenous injection of the gadolinium salt. 
Table 1. Distribution of patients by reason for examination.

\begin{tabular}{ccc}
\hline Clinical & Effective & Frequency \% \\
\hline Radiculalgia & 29 & 16.2 \\
Spinal syndrome & 11 & 6.1 \\
Motor disorder & 63 & 35.3 \\
Sensitive disorder & 7 & 3.9 \\
Radiculal pain and motor disorder & 5 & 2.8 \\
Radiculalgia and sphincter disorders & 2 & 1.1 \\
Motor/sensory/sphincter disorders & 2 & 1.1 \\
Motor and sphincter disorders & 4 & 2.2 \\
Motor and sensory disturbances & 1 & 0.6 \\
Spinal cord compression syndrome & 55 & 30.7 \\
Total & 179 & 100 \\
\hline
\end{tabular}

Table 2. Distribution of patients according to the site of the lesion.

\begin{tabular}{rcc}
\hline Segment & Effective & Frequency \% \\
\hline Cervical & 99 & 55.3 \\
Thoracic & 56 & 31.3 \\
Low back & 07 & 3.9 \\
Several segments & 17 & 9.5 \\
Total & 179 & 100 \\
\hline
\end{tabular}

The diagnostic MRI hypotheses were: degenerative (57.5\%) (Figure 1), tumor (29.6\%) (Figure 2 and Figure 3), infectious (12.3\%) (Figure 4) and vascular (0.6\%) Table 3. The intramedullary lesions consisted of astrocytomas (8.9\%), ependymomas (7.6\%) and one case, hemangioblastoma (0.6\%). The intra-dural lesions were meningiomas (1.1\%), neuromas (1.7) and epiduritis. Concerning extradural lesions, they were mainly: herniated discs (56.4\%), infectious spondylodiscitis (10.6\%) and tumor bone lesions (10.6\%). In those which concerned the affected spinal compartments, the lesions sat at the levels; extra dural (79.3\%), intra dural (4.5\%), and intra medullary (16.2\%) Table 4.

\section{Discussion}

The limitations of this study were:

- Retrospective study: Absence of old results of imaging and histology for operated patients.

- Absence of comparison of CT and MRI results for some patients as well as control MRIs

- Patients lost to follow-up. 
Table 3. Distribution of patients according to the type of lesional process.

\begin{tabular}{ccc}
\hline Type of lésion & Effective & Frequency \% \\
\hline tumor Process & 53 & 29.6 \\
Dégénérative process/herniated disc & 103 & 57.3 \\
Infectious process & 22 & 12.3 \\
Vascular process & 1 & 0.06 \\
Total & 179 & 100 \\
\hline
\end{tabular}

Table 4. Distribution of patients according to the canal compartment concerned.

\begin{tabular}{ccc}
\hline Compartiment canalaire & Effective & Frequency \% \\
\hline Extradural & 142 & 79.3 \\
Intradural & 8 & 4.5 \\
Intramedullary & 29 & 16.2 \\
Total & 179 & 100 \\
\hline
\end{tabular}

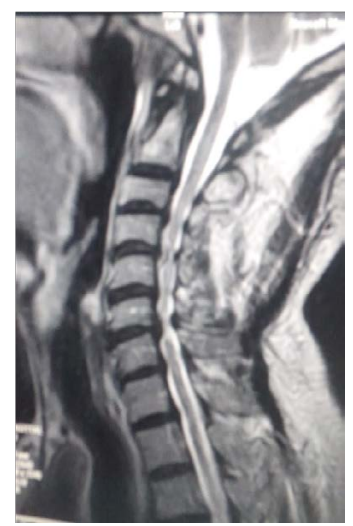

Figure 1. MRI of the cervical spine, sagittal T2 sequence. Cervical-arthritis myelopathy following compressive (extradural) herniated discs.

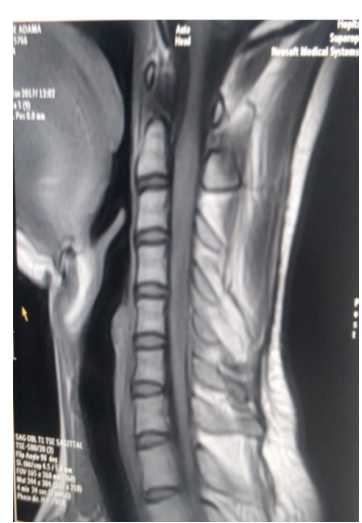

(a)

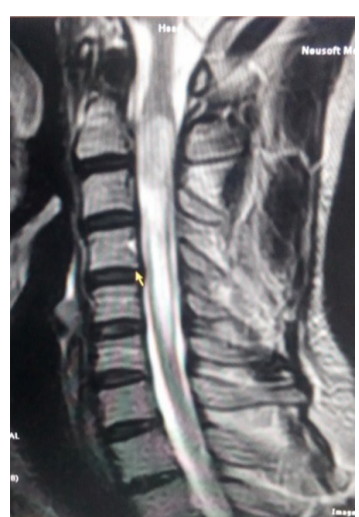

(b)

Figure 2. MRI of the cervical spine (a) Sagittal T1 injected (b) Sagittal T2. Cervical intramedullary tumor with medullary pain: ependymoma? 


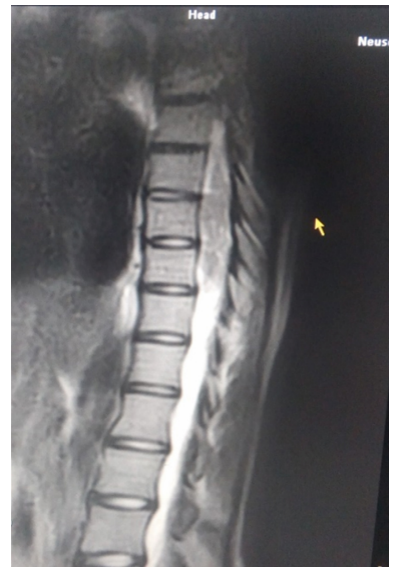

(a)

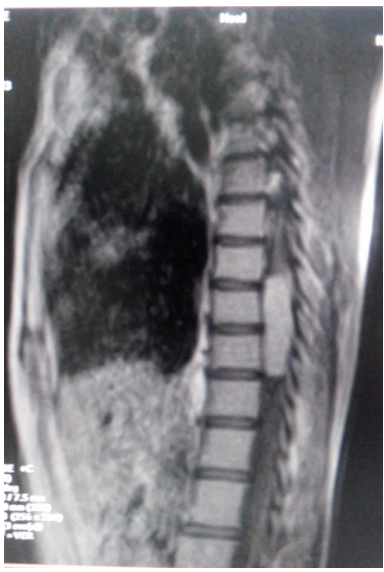

(b)

Figure 3. MRI of the thoracic spine in sagittal sequence (a) (T2) and (b) (T1 injected). Compression intra dural tumor.
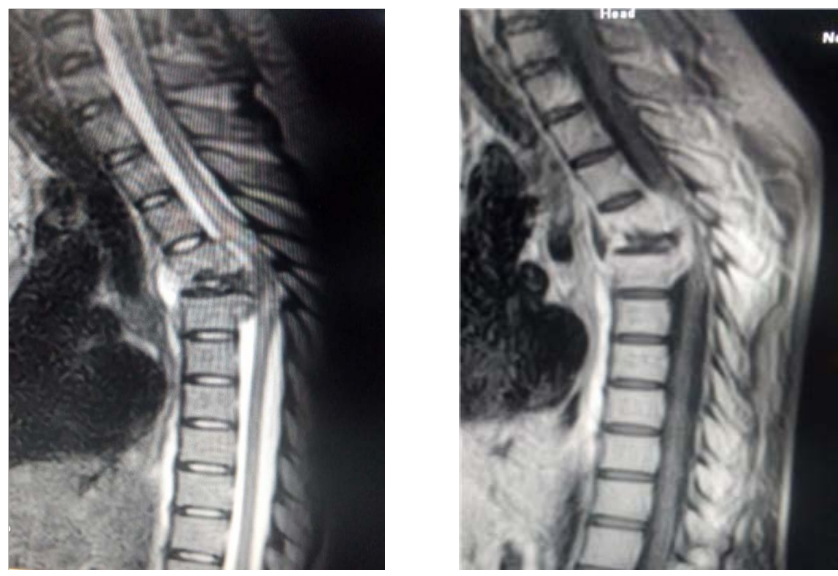

Figure 4. MRI of the thoracic spine sagittal sequence T1 and T1 gado. Acute T4-T5 spondylodiscitis with compressive anterior epiduritis and parietal abscess.

At the end of this work, MRI showed good diagnostic sensitivity to the medullary both lesion and topography. This analysis was based on MRI semiology (morphological and signal).

At the end of our work, it appears that MRI is the imaging test that performs well in the study of the spine, particularly the spinal cord and its roots.

Socio-epidemiological data:

In 02 years, we had collected 179 cases of non-traumatic spinal cord compressions on $585 \mathrm{MRI}$ of the spine, a frequency of $30.59 \%$. This high frequency is explained by the fact that, the Mali Hospital was the only center in Mali with a functional MRI machine on the one hand and on the other hand, that it was also the site of reference in neurosurgery in Mali. The average age of our patients was 53.5 years. It is comparable to those of SARA [2] in Algeria (51 years old) and KASSEGNE [6] in TOGO (53 years old). It is higher than those of GANOUNI [7] in Morocco, BADJI N [8] (48 years old), and NIANG [9] (42.6 years old) in Senegal who returned to an average age between 48 and 42.6 years. 
The male sex predominated in our series with a sex ratio of 3.7. This corroborates with other studies: SARA M. [2] in Algeria 3. KASSEGNE I. [6] in Togo, and DIOMANDE M [10] in Abidjan. However, BADJI N. [8] in Dakar was reported a female predominance (0.6). We did not find a scientific explanation for this male predominance.

Although pain is the first manifestation of spinal cord compression, motor disorders were the symptom that most motivated us to perform our MRI exams (41\%). Root pain came in 2nd position (16.2\%) [9].

Our study was carried out using a low-field MRI machine, while most of the similar studies were carried out on high-field machines [7] [8] [9] [11]. As a result, they were able to benefit from better spatial resolution. It had no impact on our MRI diagnosis

The sagittal (T1 and T2) and axial T2 sequences were performed systematically. This protocol is recommended by the literature [6] [8] [11] [12].

The intravenous injection of gadolinium salt was decided according to the result of the sequences not injected as recommended in the literature [5] [8] [12]. It is performed when a tumor or infectious process is discovered.

MRI with or without the injection of gadolinium salt is the first benchmark examination when spinal cord injury is clinically suspected. It allows the study of the spinal cord in the three planes of space and to appreciate the surrounding structures. It determines the lesion topography: extra medullary, intradural or intramedullary [12].

With regard to the spinal stages reached; the lesions were located at the levels: cervical (55.3\%). thoracic (31.3\%), lumbar (3.9\%) and were multi-segmental (9.5\%). Our data are different from those of BADJI [8] and DIOMANDE [10] who found in their series the back injuries in $42 \%$ and $56.1 \%$ respectively. For SARA [2], the lumbosacral segment was the most concerned (62\%).

In our series, extradural lesions (79.3\%) were dominated by degenerative processes and compressive herniated discs. Our data were consistent with certain data from the literature [1] [3]. On the other hand, the studies of BADJI [8], NIANG [9], BENOUNA [12] and MIREAU [1] were dominated by infectious processes.

Intramedullary localizations represented $16.2 \%$ of the cases which is close to the results of SARA [2], GANOUNI [7] and NASRI [11]. This could be explained by the limited number of MRI installations. So, it was not systematically requested in disco-vertebral infections. Intra dural and intramedullary lesions were the prerogative of tumor processes, which corroborated with the literature [2] [7] [8] [9].

1) Depending on the spinal segment: Table 5

Degenerative processes largely predominated on the cervical floor, superimposable on the BADJI series [8], Tumor pathologies predominated on the other two stages, which was superimposed on other similar studies [10] [13] [14].

2) Depending on the canal compartment: Table 6 
Table 5. Distribution according to the spinal level.

\begin{tabular}{ccccc}
\hline Segment Spinal & Our study & Badji [8] & Diomande [10] & Sara [2] \\
\hline Cervic & $55.3 \%$ & $32 \%$ & $30.6 \%$ & $20 \%$ \\
Thoracic & $31.3 \%$ & $42 \%$ & $56.1 \%$ & $17 \%$ \\
Low back & $3.9 \%$ & $18 \%$ & $3.9 \%$ & $62 \%$ \\
Several Segments & $9.5 \%$ & $8 \%$ & $9.4 \%$ & \\
\hline
\end{tabular}

Table 6. Distribution of lesions according to the canal compartment.

\begin{tabular}{ccccccc}
\hline Canal compartment & Ourstudy & Badji [8] & Niang [9] & Nasri [11] & Sara [2] & Benouna [12] \\
\hline Extradural & $79.3 \%$ & $87 \%$ & $70 \%$ & $72 \%$ & $67.5 \%$ & $91 \%$ \\
Intradural & $4.5 \%$ & $8 \%$ & $25 \%$ & $15 \%$ & $20 \%$ & $5 \%$ \\
Intramedullary & $16.2 \%$ & $5 \%$ & $5 \%$ & $13 \%$ & $12.5 \%$ & $4 \%$ \\
\hline
\end{tabular}

Extradural etiologies were dominated by degenerative processes and herniated discs. They were different from those of GANOUNI [6], SARA [2] and BADJI [8], who found an infectious etiology. This could be explained by the fact that in our place of study MRI is not systematically indicated in the suspicions of disco-vertebral infectious pathologies. Spinal metastases came second in terms of frequency; which corroborated with the series of GANOUNI [6], BADJI [8], and BOUHAFA [15].

In the intramedullary and intradural compartments, the etiologies were dominated by tumor processes, as noted by GANOUNI [6], SARA [2], and BADJI [8].

\section{Conclusion}

Spinal cord compressions are a diagnostic and therapeutic emergency. The etiologies are very varied. MRI remains the benchmark examination for diagnosis. It makes it possible to analyze the anatomical elements, to specify, the site, the extent of the lesion and to provide elements of etiological orientation.

\section{Contributions from Authors}

All the authors contributed to the conduct of this work. All authors also declare that they have read and approved the final version of the manuscript.

\section{Consent}

For this work, we have received the patient's approval; that of the head of the service and the director of Mali Hospital.

\section{Conflicts of Interest}

The authors declare no conflicts of interest regarding the publication of this paper. 


\section{References}

[1] Mireau, E., Filho, G., Dib, A. and Gaudart, S. (2009) Slow Spinal Compression EMC, Neurology, 17-655-A-10. https://doi.org/10.1016/S1634-7072(10)70504-3

[2] Sara, M. and Mendira, M. (2016) Final Thesis in Medical Studies. Faculty of Medicine University Abderraman Mir Algeria.

[3] George, B. (1998) Slow Spinal Compression. EMC Elsevier, Paris, Practice of Medicine, 5-0980, 4 p.

[4] Michel, J.L. and Lhoste-Trouilloud, A. (1994) Radiological Anatomy of the Spine. Chir. App. Locomotor-15-840.

[5] Luciani, A. and Rahmouni, A. (2017) MRI in Clinical Practice. Elsevier Masson, SAS, Paris, 235-252.

[6] Kassegne, I., Sakiye, K., Kanassoua, K., Beketi, A.K., Badiane, S.B. and Balogou, K.A.A. (2013) Management of Slow Spinal Cord Compressions in Togo. Médecine et Santé Tropicales, 23, 206-210. https://doi.org/10.1684/mst.2013.0177

[7] Ganouni Nci, E.L., Khalil, M.R., Hiroual, M.R., El Idrissi, I., Haddi, M., Aït Benali, S., Essadki, O. and Ousehal, A. (2009) Contribution of MRI in Slow Spinal Compressions of Tumor and Infectious Origin. Radiology Sheet, 49, 251-262. https://doi.org/10.1016/S0181-9801(09)72375-9

[8] Badji, N., Deme, H., Akpo, G., Ndong, B., Toure, H., Diop, S.B. and Niang El, H. (2016) Contribution of MRI in the Management of Non-Traumatic Slow Spinal Cord Compressions. The Pan African Medical Journal, 24, 221.

[9] Niang El, H. and Diop, A. (2016) MRI in the Etiological Assessment of Spinal Cord Compressions at Fann's CHU. http://www.sfrnet.com

[10] Diomandé, M., Nseng-Nseng, R., Kouamé-Assouan, A., Gbané-Koné, M., Coulibaly, A., Djaha, K., Ouattara, B., Eti, E., Daboiko, J. and Kouakou, M. (2015) Slow Spinal Compression: Prevalence and Etiologies, Experience in the Rheumatology Department of the Cocody University Hospital in Abidjan. Moroccan Journal of Rheumatology, 33, 27-30.

[11] Nasri, S., Marzouki, Z., Aichouni, N., Amar, A.O., Neftah, C., Boutaha, I. and Skiker, I. (2017) Place of MRI in the Diagnosis of Spinal Cord Compression. Journal of Neuroradiology, 44, 107-110. https://doi.org/10.1016/j.neurad.2017.01.087

[12] Bennouna, S., Ibn Khayat Zougari, S., Kamaoui, I., Houssaini, N., Tizniti, S., Belahsen, F. and Maaroufi, M. (2014) Slow Spinal Compression: Diagnostic Approach (about 130 Cases). Neurological Review, 170, A27. https://doi.org/10.1016/j.neurol.2014.01.173

[13] Langenskiöld, E. (2003) Metastatic Spinal Compression. Info Kara, 18, 130-135. https://doi.org/10.3917/inka.033.0130

[14] Khalil, M., Hiroual, M., El Idrissi, I., Haddi, M., Aït Benali, S. and EL Ganouni, N. (2007) MRI Contribution in Slow Spinal Cord Compressions (about 53 Cases). Journal of Radiology, 88, 1557.

[15] Bouhafa, T., Elmazghi, A., Masbah, O. and Hassouni, K. (2014) Spinal Cord Compression of Metastatic Origin. The Pan African Medical Journal, 19, 209. https://doi.org/10.11604/pamj.2014.19.209.3695 


\section{Individual Investigation Sheet}

File number...

Date of MRI: ........./

\section{CIVIL STATUS OF THE PATIENT}

Q1. Age:

Q2. Gender:

1) Male

2) Female.

Q3. Reason for examination
1) Spinal Claudication;
2) Radiculalgia;
3) Spinal syndrome;
4) Motor disorders;
5) Sensitive disorders;
6) Sphincteric disorders;
7) ROT troubles;
8) Radiculalgia and Motor Disorders;
9) Radiculalgia and sphincter disorders;
10) Compulsory spinal cord compression;
11) Motor and sphincter disorders;
12) Motor and sensory disturbances;
13) Motor, sensory and sphincter disorders

\section{TECHNIQUES:}

Q4. T1 \.......... /:

1) Axial;

2) Coronal;

3) Sagittal

Q5. T2 \

1) Axial;

2) Coronal;

3) Sagittal

Q6. STIR \....../:

1) Axial;

2) Coronal;

3) Sagittal

Q7. T1 Intra venousInjection de gadolinium

1) Yes;

2) No

\section{IRM DATA:}

Q8. Spinal segment $\backslash \ldots . .$. /:
1) Cervical;
2) Thoracic;
3) Lombar;
4) Multiple floors

Q9. Extent of the lesion $\backslash$......../:
1) A floor;
2) Two floors;
3) Three floors;
4) More than three floors Q10. Number of lesions $\backslash \ldots . . . . /$ :

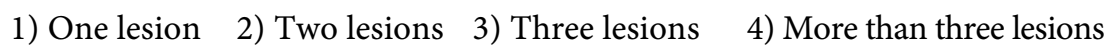
Q11. Type of lesion \...... /:
1) Tumor process
2) Generative process
3) Infectious process
4) Vascular process

Q12. Canal compartment $\backslash$......../:
1) Intramedullary
2) Intradural extramedullary
3) Extradural

Q13. Diagnostic hypotheses:
1) Astrocytoma;
2) Ependymoma;
3) Neuroma
4) Meningioma;
5) Hemangioblastoma
6) Arachnoid cyst
7) Tuberculous spondylodiscitis
8) Spondonodiscitis pyogenic;
9) Herniated disc
10) Primary tumor of the spine
11) Vertebral and epidural metastasis
12) Primary epidural abscess
13) Arthritis lesion

A) All the authors declare having read and give their consent for the publication.

B) Our article is original and has never been submitted or published in another newspaper.

C) Concerning names, emails and affiliations. 